\section{Monozygotic twins discordant for Rubinstein-Taybi syndrome}

SUMMARY A pair of male monozygotic twins discordant for Rubinstein-Taybi syndrome is reported. Monozygosity of the twins was established using blood grouping, typing of serum proteins, isozymes, HLA, and chromosomal heteromorphisms. The twins are the first twin pair discordant for the syndrome in which monozygosity has been firmly established. The pathogenesis of the syndrome is discussed in relation to the occurrence of both discordant and concordant monozygotic twins.

Since Rubinstein and Taybi ${ }^{1}$ described the syndrome which now bears their names, more than 120 cases have been reported. The main clinical features of the syndrome are mental retardation, broad thumbs and big toes, and a characteristic facies.

The aetiology of the syndrome is controversial. While most of the reported cases have been sporadic, affected sibs have been described in a few families. ${ }^{23}$ Simpson and Brissenden ${ }^{4}$ found two affected among 243 sibs of probands, a recurrence risk of about $0.8 \%$, which is substantially greater than the population risk of $0.003 \%$. Der Kaloustian et al described an affected brother and sister from consanguineous parents. Father-daughter incest produced another case. ${ }^{6}$ Concordance for the syndrome has been reported in three pairs of monozygotic twins. ${ }^{7}$ All these findings suggest that genetic factors are operative. However, the lack of much familial aggregation argues against dominant, recessive, or multifactorial inheritance. Normal karyotypes have been observed in almost all cases, although inconsistent chromosomal variations have been noted occasionally. Schinzel and his colleagues, ${ }^{7}$ in a world-wide survey of congenital structural defects in like-sexed twins, briefly listed two pairs of probable monozygotic twins and another two pairs of like-sexed twins, of which three pairs were discordant for the syndrome. The remaining twin pair was concordant. Again, the evidence is against single gene inheritance. The zygosity of these twins, however, has not been firmly established.

We wish to describe a pair of twins, highly likely to be monozygous, one of whom is entirely normal while the other has the classical features of the syndrome.

Received for publication 7 October 1980

\section{Case reports}

The twins were born at 37 weeks' gestation to a 29-year-old mother and a 31-year-old father. At? birth a single placenta was noted. There was noㅡ. history of drug ingestion, $x$-ray exposure, or vira illness during pregnancy. The parents were healthy and unrelated. There was an elder sister who ap peared normal. No other malformations or develop- $\overrightarrow{0}$ mental disorders were known in the family.

TWIN 1 (FIG $1 \mathrm{a}, \mathrm{c}$ )

He weighed $2300 \mathrm{~g}$ at birth. He suffered from feeding difficulties and recurrent respiratory infections during infancy. When seen at the age of 4 years 8 months he weighed $11 \cdot 5 \mathrm{~kg}(-2 \cdot 1 \mathrm{SD})$, his height was $87 \cdot 3 \mathrm{~cm}$ $(-4 \cdot 2 \mathrm{SD})$, and his head circumference was $47 \cdot 0 \mathrm{~cm}$ $(-2 \cdot 2 \mathrm{SD})$. He was not toilet-trained and spokeo about four words. His IQ was 53. Physical examination revealed a boy with the following features prominent forehead, antimongoloid slanting of the palpebral fissures, arched eyebrows, ptosis of then eyelids, long eyelashes, internal strabismus (right) $\overrightarrow{\overrightarrow{0}}$ glaucoma (right), corneal opacities (right), a broado nasal bridge, an aquiline nose with the nasal septum extending below the alae, a narrow palate, mildo micrognathia, broad thumbs and big toes, partiak cutaneous syndactyly of the right big and seconos toes, hypoplasia of the toenails, pectus excavatum: inguinal testis (right), hirsutism, and stiff gait. $A n_{\mathfrak{B}}^{\mathbb{D}}$ unusual smile has been observed frequently. He was? pleasant and related on an infantile level to other 3 people, but was uncooperative.

Radiological examination revealed broad and short terminal phalanges of the thumbs and the right big toe, duplication of the proximal phalanx, and bifid proximal end of the terminal phalanx of the left big toe (fig 2). The foramen magnum was not. evaluated. The bone age was estimated at 4 years.

TWIN 2 (FIG 1 b, d)

He was normal at birth with a weight of $2220 \mathrm{~g}$ ? At the age of 4 years 8 months his weight was $14 \cdot 30$ $\mathrm{kg}(-0.7 \mathrm{SD})$ and his height was $96.8 \mathrm{~cm}(-1 \cdot 1 \mathrm{~N}$ SD). Roentgenographic examination of the skeletono revealed no abnormality. His IQ was 116 .

Chromosomal analysis with $G$ and $Q$ banding showed a normal karyotype in both twins, their elder sister, and the parents.

Dermatoglyphs of the twins were as follows.? Twin 1. Left hand: whorl (W), tented arch, radiales loop (Lr), W, W; right hand: W, double loop (DL), ulnar loop (Lu), W, W. Twin 2. Left hand: W, W, DL, DL, DL; right hand: W, Lu, Lu, Lu, Lu. Palmar品 features of twin 1 showed axial triradii at $t$ and $t$, $\frac{\pi}{D}$ positions in both hands, and a proximal loop pattern 
(a)
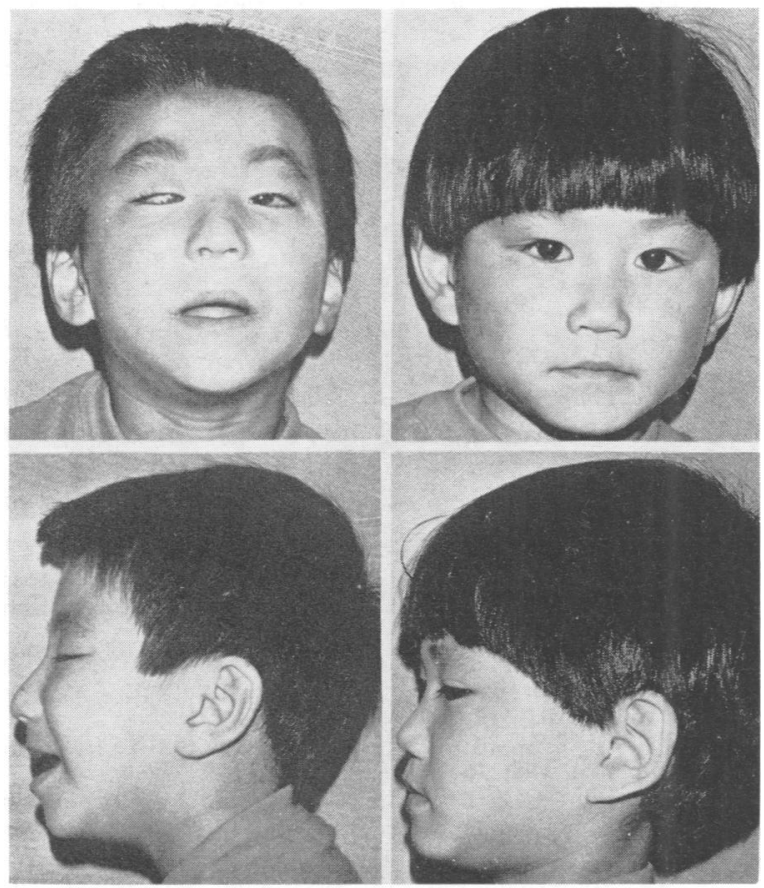

(c)

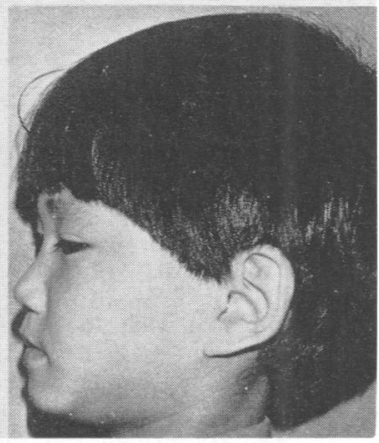

(d) (b)

FIG 1 The twins at 4 years 8 months. Twin 1 ( $a$ and $c$ ) with Rubinstein-Taybi syndrome and twin 2 ( $b$ and $d)$ with an apparently normal phenotype.
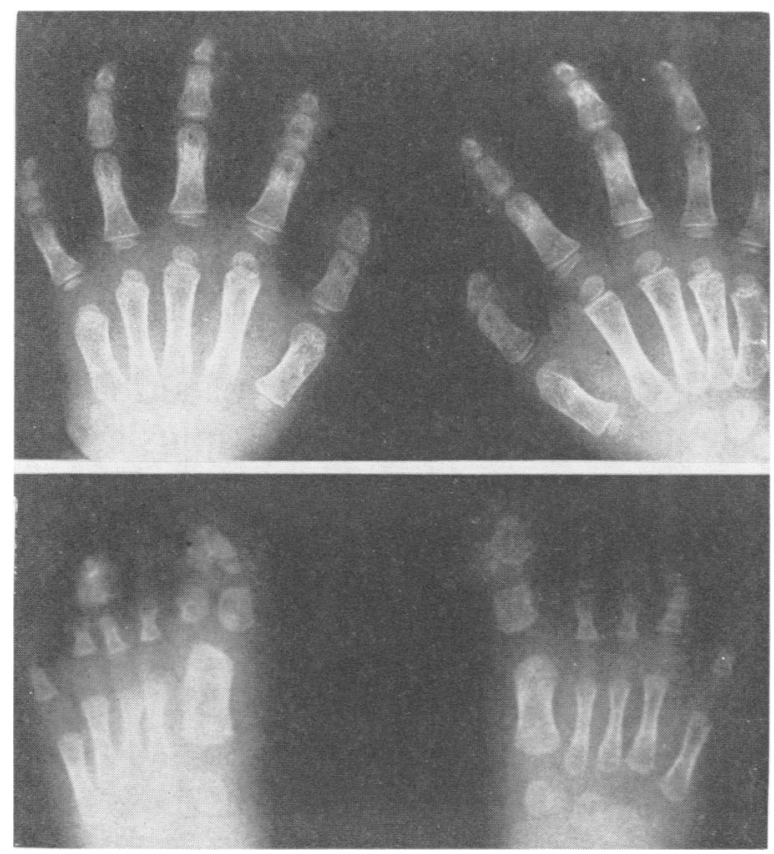

FIG $2 X$-rays of the hands and feet of twin 1 showing short broad terminal phalanges of the thumbs and big toes and duplication of the proximal phalanx and bifid distal phalanx of the left big toe. 
TABLE Results of analysis of gene markers

\begin{tabular}{|c|c|c|c|}
\hline Marker & Father & Mother & Both twins \\
\hline Sex & $\mathbf{M}$ & $\mathrm{F}$ & $\mathbf{M}$ \\
\hline $\begin{array}{c}\text { Blood groups } \\
\text { ABO } \\
\text { MNSs } \\
\text { Kidd }\end{array}$ & $\begin{array}{l}\text { A } \\
\text { Ns } \\
a+b-\end{array}$ & $\begin{array}{l}\mathrm{O} \\
\text { MNs } \\
\mathbf{a}+\mathbf{b}+\end{array}$ & $\begin{array}{l}\text { A } \\
\text { MNs } \\
a+b+\end{array}$ \\
\hline$\underset{\mathrm{Gm}}{\text { Serum proteins }}$ & $\begin{array}{c}1,-2,-3, \\
-5,16,21\end{array}$ & $\begin{array}{l}1,2,-3, \\
-5,-16,21\end{array}$ & $\begin{array}{l}1,2,-3, \\
-5,-16,21\end{array}$ \\
\hline $\begin{array}{l}\text { Hp } \\
\text { Isoenzymes } \\
\text { PGM }_{1} \\
\text { GPT } \\
\text { EsD }\end{array}$ & $\begin{array}{l}2-1 \\
\mathrm{a} 2-\mathrm{a} 2 \\
1-1 \\
1-1\end{array}$ & $\begin{array}{l}2-1 \\
\text { a3-a2 } \\
2-1 \\
2-1\end{array}$ & $\begin{array}{l}2-1 \\
\mathrm{a} 3-\mathrm{a} 2 \\
1-1 \\
2-1\end{array}$ \\
\hline $\begin{array}{c}\text { HLA } \\
\text { A } \\
\text { B } \\
\text { C }\end{array}$ & $\begin{array}{l}26,2 \\
15,7 \\
-, \mathrm{W} 3\end{array}$ & $\begin{array}{l}2, \mathrm{~W} 33 \\
\text { W35, - } \\
\text { w3, w1 }\end{array}$ & $\begin{array}{l}26,2 \\
15, W 35 \\
-, W 3\end{array}$ \\
\hline
\end{tabular}

Systems tested but uninformative: Rh, Duffy, Gc, P, ACP, Km, ear wax type.

in the thenar areas, bilaterally. Twin 2 showed axial triradii at $t$ and $t^{\prime}$ positions, bilaterally, and a proximal loop pattern in the thenar area of the left hand. The probability of the twins being monozygotic was calculated to be $0 \cdot 9998$, using blood group antigens, serum proteins, isozymes, HLA, and ear wax type (table), and as 0.996 using sequential $Q$ and $R$ banding heteromorphisms. The combined probability was 0.999998 .

\section{Discussion}

The occurrence of the Rubinstein-Taybi syndrome in one of a pair of monozygotic twins is incompatible with single gene control. It is conceivable that a minor chromosomal change, beyond the limits of resolution of existing methods, occurred in twin 1 after twin development. The chromosomes of patients with the syndrome have usually been reported to be normal. In about $3 \%$ of the patients a structural abnormality of the chromosomes has been seen. However, the nature of the chromosomal abnormality has varied greatly; thus, assignment of an aetiological role to the chromosome abnormality, even in these cases, would not seem warranted.

It seems that our twins are the first with proven monozygosity discordant for the syndrome. Altogether, eight pairs of monozygotic or like-sexed twins with the Rubinstein-Taybi syndrome have been reported. ${ }^{7}$ Of these, four pairs were concordant for the syndrome and the other four pairs were discordant. Multifactorial inheritance, as suggested by Roy et $a l^{8}{ }^{8}$ is compatible with the occurrence of both concordant and discordant monozygotic twins, but not with the lack of much familial aggregation. No graded severity among cases and close relatives has been noted.
Schinzel et $a l^{7}$ raised the possibility that the syn-क drome is the consequence of a single early localised malformation giving rise to the malformation com plex. The malformation complex encompasses theo initial malformation, poor formation of a tissueo during morphogenesis, plus its secondarily derived $\overline{\bar{n}}$. defects. There is a need for further family studies of patients with the syndrome.

T KaJiI,* K Hagiwara,* M Tsukahara, $\stackrel{*-}{\circ}$ H NaKaJima, $\dagger$ and Y FuKUda ${ }^{+}-$

* Department of Pediatrics, Yamaguch $\vec{\omega}$ University School of Medicine, Ube; $\dagger$ the

Department of Forensic Medicine, Tokyo Medica合 and Dental University, Tokyo; and $\ddagger$ the 2 nd Department of Surgery, Hiroshima University $y_{+}^{\infty}$ School of Medicine, Hiroshima, Japariw

References

1 Rubinstein JH, Taybi H. Broad thumbs and great toes and facial abnormalities: a possible mental retardationsyndrome. Am J Dis Child 1963:105:588-608.

2 Johnsson CF. Broad thumbs and broad great toes with facial abnormalities and mental retardation. $J$ Pediate 1966;68:942-51.

3 Takeuchi M. Rubinstein's syndrome in two siblings $\overrightarrow{0}$ Gumma J Med Sci 1966;15:17-22.

4 Simpson NE, Brissenden JE. The Rubinstein-Taybisyndrome: familial and dermatoglyphic data. Am J Hum Genet $1973 ; 25$ :225-9.

5 Der Kaloustian VM, Afifi AK, Sinno AA, Mire J. Thes Rubinstein-Taybi syndrome: clinical and muscle electrōo microscopic study. Am J Dis Child 1972;124:897-902.

6 Padfield CJ, Partington MW, Simpson NE. The् Rubinstein-Taybi syndrome. Arch Dis Child 1968;43? 94-101.

7 Schinzel AAGL, Smith DW, Miller JR. Monozygotio twinning and structural defects. J Pediatr 1979;95:921-30-

8 Roy FH, Summitt RL, Hiatt RI, Hughes JG. Ocula manifestations of the Rubinstein-Taybi syndrome. Case. report and review of the literature. Arch Ophthalmo $1968 ; 79: 272-8$.

Requests for reprints to Professor T Kajii, Depart $\overline{3}$ ment of Pediatrics, Yamaguchi University School of Medicine, Ube, Japan 755.

Hydrocephalus, agyria, pseudoencephalocele, retinal dysplasia, and anterior chamber anomalies

SUMMARY An infant presenting with hydro $\frac{N^{N}}{\sigma}$ cephalus, pseudoencephalocele, agyria, an ocular defects, consisting of anterior chambef anomalies and retinal dysplasia, is reportedes This is thought to be a further case of ano autosomal recessive syndrome of which sie cases have been previously described.

Received for publication 28 October 1980 